\title{
A construção da escrita acadêmica colaborativa estudantil em conversas digitalizadas
}

DOI: http://dx.doi.org/10.21165/el.v50i3.3040

\section{Eliana Maria Severino Donaio Ruiz'}

\section{Resumo}

Este trabalho apresenta os resultados de uma pesquisa-ação, de abordagem qualiquantitativa, que analisou a construção do texto colaborativo por aprendizes de escrita acadêmica em interações via ferramenta fórum da plataforma Moodle e do aplicativo WhatsApp. Foram investigadas conversas digitalizadas de estudantes de Letras de uma universidade pública paranaense, visando a produção colaborativa de resumos e resenhas. Numa concepção dialógica de linguagem, os aportes teóricos contemplam estudos sobre uso de tecnologias digitais na educação, escrita colaborativa e letramentos acadêmicos. Os resultados apontam para uma herança do letramento autônomo vivenciado pelos sujeitos na educação básica, demandando, por parte do professor universitário, mais atenção para com aspectos de mediação e planejamento com apoio de tecnologia digital, envolvidos seja no processo de produção escrita colaborativa, em geral, ou acadêmica, em particular.

Palavras-chave: escrita colaborativa; tecnologia digital; letramento acadêmico; fórum do Moodle; WhatsApp.

1 Universidade Estadual de Londrina (UEL), Londrina, Paraná, Brasil; elianaruiz@uel.br; https://orcid.org/0000-0002-7169-8464 


\title{
The construction of collaborative student academic writing in digitalized conversations
}

\begin{abstract}
This study presents the results of action research, with a qualitative and quantitative approach, that analyzed the construction of collaborative text by academic writing learners in interactions via the forum on the Moodle platform and the WhatsApp applicative. Digitalized conversations of Letras/Languages students from a public university in Paraná (Brazil) were investigated, aiming at the collaborative production of abstracts and reviews. In a dialogical conception of language, the theoretical contributions include studies about the digital technologies used in education, collaborative writing and academic literacies. The results point to an autonomous literacy experienced by the subjects in basic education, demanding more attention to mediation and planning with digital technology support aspects involved by the professor, more attention to mediation and planning aspects involved either in the collaborative writing production, in general, or academic, in particular.
\end{abstract}

Keywords: collaborative writing; digital technology; academic literacy; forum on the Moodle; WhatsApp.

\section{Considerações iniciais}

Já se tornou truísmo afirmar que o século XXI tem sido palco de uma realidade tecnológica inigualável, ao passo que a cibercultura (LEVY, 1999) toma espaço em todas as áreas do conhecimento. A tecnologia digital, cada vez mais presente no cotidiano da sociedade, vem ressignificando o modus operandi do nosso processo de interação e alterando nossas práticas comunicativas. Socializamo-nos em ambientes virtuais com conhecidos e desconhecidos, desterritorializamo-nos, rompendo barreiras geográficas por meio da comunicação instantânea, rearranjamos nossas transações com compras e pagamentos pela internet, ensinamos e aprendemos por meio de cursos a distância, num rol de inovações sem fim.

Como reflexo desse universo marcado pela acentuada evolução da tecnologia, proliferamse, em vários campos do saber, pesquisas que investigam as potencialidades dos recursos tecnológicos digitais para a dinamização dos processos educacionais. O entendimento de que a escola não pode ficar alheia às mudanças decorrentes da crescente integração das Tecnologias Digitais de Informação e Comunicação (TDIC) à nossa rotina social e profissional tem levado à defesa, inclusive por documentos oficiais de ensino (BRASIL, 2018), de que é necessário explorar as possibilidades tecnológicas nos processos de ensino, de maneira a promover a produção e a disseminação de conhecimento. O blended learning (modalidade de ensino híbrido que mescla o presencial e o a distância) e o uso 
das redes sociais para compartilhamento formal de conhecimento, por exemplo, têm sido apontados como de grande potencial pedagógico (MATEUS; ORVALHO, 2004; PEREIRA, 2015).

Nesse contexto, com o advento da Web 2.0 e seu novo ethos (CASTELLS; CARDOSO, 2005), baseado na participação em massa do processo produtivo, na distribuição de expertise, na celebração da "inclusão" e no descentramento da noção de autoria, intensifica-se o interesse pela produção compartilhada e pela colaboração, em que dois ou mais sujeitos, com habilidades complementares, interagem para criar um conhecimento que nenhum deles tinha previamente ou poderia obter porconta própria. Eganha espaço a aprendizagem colaborativa, entendida como um processo de construção do conhecimento decorrente da participação, envolvimento e contribuição ativa dos sujeitos na aprendizagem uns dos outros (TORRES; AMARAL, 2011).

Seguindo essa linha de interesse pela colaboração, alguns pesquisadores têm focalizado, mais especificamente, a importância do trabalho colaborativo de produção escrita (SOUNDERS, 1989; LOWRY; CURTIS; LOWRY, 2004; PINHEIRO, 2011). E a modalidade de escrita em conjunto passa a ser vista como promissora estratégia de aprendizagem, na medida em que sujeitos podem produzir melhores resultados relativamente a uma atuação individual como produtores de texto, dada a complementaridade de conhecimentos, capacidades e pontos de vista, permitindo a geração de alternativas mais viáveis para a resolução de problemas comuns (HORTON et al., 1991).

Embora com propósitos diversos e alheios às pautas que se colocam no entremeio do campo educacional vinculado à tecnologia e às questões específicas que vêm sendo postas no que se refere à produção colaborativa de textos, identificamos que se foi constituindo, também nos últimos anos, um campo de estudos voltado aos letramentos acadêmicos (LEA; STREET, 1998; LILLIS; SCOTT, 2007). Com o exame das práticas de escrita em contexto universitário, seus pesquisadores vêm explorando contribuições de várias áreas e subáreas do conhecimento. E concebendo o letramento como prática social, preconizam que, mais do que o conhecimento do código da língua em si mesmo, o letramento diz respeito aos usos e às funções da escrita dentro das práticas sociais em que se insere (LEA; STREET, 1998; STREET, 2003).

Tomando, então, como referência esses três campos de estudo contemporâneos - uso das TDIC em processos educativos, escrita colaborativa e letramentos acadêmicos -, este trabalho, fundado na concepção dialógica de língua(gem) (BAKHTIN, 2003), pretende apresentar os resultados de uma pesquisa-ação vinculada a um projeto maior que investiga o ensino e a aprendizagem da escrita em ambientes mediados por tecnologia 


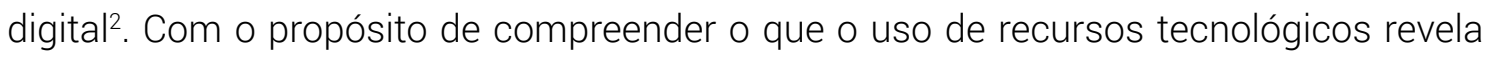
sobre a construção da escrita colaborativa acadêmica estudantil, investigamos trocas de mensagens assíncronas escritas por aprendizes, antes da pandemia, em fóruns de discussão da plataforma Moodle e em conversas de grupos de WhatsApp, para a produção de resumos e resenhas. Nossa análise, de natureza qualiquantitativa, esteve focada nas seguintes questões: de que trata a conversa digitalizada de estudantes de Letras sobre a escrita colaborativa de um texto acadêmico? Que aspectos do processo de produção esses aprendizes tematizam ou privilegiam quando discutem, através de ferramentas digitais, a escrita colaborativa de resumos e resenhas?

A seguir, apresentamos o percurso teórico, metodológico e analítico da investigação realizada.

\section{Alguns apontamentos teóricos}

Retomamos aqui, em linhas gerais, os conceitos principais dos referenciais teóricos com os quais este trabalho dialoga, atinentes aos estudos sobre letramentos acadêmicos e escrita colaborativa.

Os trabalhos sobre letramentos acadêmicos se desenvolveram a partir dos chamados Novos Estudos de Letramento - New Literacy Studies (NLS) (conforme STREET, 1984, 1995; BARTON, 1994; GEE, 1996). Esses autores consideram que são necessárias mais que habilidades para resolver alguns dos problemas que os estudantes enfrentam nas atividades de leitura e escrita, pois os modos pelos quais as pessoas usam a leitura e a escrita são atrelados a concepções de conhecimento, identidade e formas de ser e estar nas práticas sociais. Paralelamente ao que denominam letramento autônomo - que entende a escrita um produto completo em si mesmo, desvinculada de um contexto social e atrelada a habilidades pessoais - contrapõem o letramento crítico, que dá ênfase aos aspectos ideológicos das práticas sociais de leitura e escrita. Essa visão leva ao termo letramentos, no plural, a que o sujeito fica exposto no seu contexto social, já que são inúmeros, pois dependem dos diferentes contextos em que se inserem a leitura e a escrita.

Baseando-se em teorias de leitura, escrita e letramento entendidos como práticas sociais, "Lea e Street $(1998,1999)$ defenderam nova abordagem para a compreensão da escrita e do letramento do estudante em contextos acadêmicos que desafiam o

2 Projeto de pesquisa TDIC-ENALP - Tecnologias Digitais no Ensino-Aprendizagem de Língua Portuguesa, aprovado pelo comitê de ética da UEL sob número: 3.453.420, integra os projetos do grupo de pesquisa FELIP - Formação e Ensino em Língua Portuguesa - cadastrado e certificado no Diretório dos Grupos de Pesquisa no Brasil (DGP - CNPq). 
modelo dominante de déficit" (LEA; STREET, 2014, p. 478)³. Considerado referência para a constituição e a manutenção do campo dos letramentos acadêmicos, o estudo realizado em 1998 no Reino Unido (LEA; STREET, 1998), sobre textos de alunos em contexto de práticas institucionais, identificou lacunas conceituais na maneira como estudantes e professores compreendem a produção textual. E propôs a existência de três modelos de ensino da escrita no contexto universitário, mas também passíveis de serem aplicados na educação básica, denominados de habilidades cognitivas, socialização acadêmica e letramentos acadêmicos.

O modelo das habilidades cognitivas entende a escrita e o letramento como capacidades individuais e focaliza os aspectos linguísticos técnicos e instrumentais da língua (como ortografia e gramática), entendendo que o aprendiz possa fazer transferências de conhecimento de um contexto para outro. Já o modelo de socialização acadêmica foca a aculturação do aluno nos discursos e gêneros que são específicos das disciplinas e áreas temáticas da universidade, na expectativa de que assimilem os modos de falar, raciocinar, interpretar e usar as práticas de escrita aí valorizadas. Contrapondo-se a ambos os modelos, que trabalham a partir da ideia de déficit do alunado, o modelo de letramentos acadêmicos, defendido pelos pesquisadores, centra-se nas questões epistemológicas mais complexas, dinâmicas e situadas que envolvem os processos sociais vinculados à academia, como relações de poder entre pessoas e instituições, além de questões de identidades sociais.

Os estudos em letramento acadêmico visam, dessa forma, entender como a escrita é utilizada em contexto universitário, com quais finalidades e que implicações tem para o estabelecimento de relações de poder, construções identitárias e concepções relativas ao ensino da escrita no ensino superior. As proposições e os questionamentos desse campo de estudos constituem, pois, um primeiro alicerce no qual nos apoiamos.

Um segundo referencial pertence ao campo dos estudos sobre escrita colaborativa. Diferentemente da escrita individual, em que normalmente se escreve sozinho e em silêncio, a escrita colaborativa é assim chamada por estudiosos como Wigglesworth e Storch (2009), mas, como bem lembra Felipeto (2019), também é referenciada como redação cooperativa por Gaulmyn, Bouchard e Rabatel (2001), ou como redação conversacional por Brassac (2001). Trata-se de uma situação na qual dois ou mais participantes assumem a tarefa de escrever conjuntamente um único texto, interagindo por meio do diálogo conversacional. Na escola, pode ser entendida como uma situação didática que coloca aprendizes para conversarem acerca de um texto a ser escrito a várias mãos e olhos e mentes.

3 Autocitação dos autores. 
Com base em trabalho de Horton et al. (2004) e empregando uma terminologia aplicável ao campo interdisciplinar, Lowry, Curtis e Lowry (2004) propõem uma taxonomia para a descrição do processo de escrita colaborativa que se funda em quatro categorias: modos, papéis, atividades e estratégias. Em razão do espaço que aqui nos é concedido, focalizaremos, em função de nossas perguntas de pesquisa, apenas os modos e as atividades de escrita colaborativa.

Os modos de escrita colaborativa, segundo esses pesquisadores, concernem às decisões atinentes ao grau de proximidade física e de sincronicidade do grupo: no mesmo local e ao mesmo tempo; em locais diferentes e ao mesmo tempo; no mesmo local e em tempos diferentes; e em locais diferentes e em tempos diferentes.

Já as atividades deescrita colaborativa correspondem às várias etapas ou fases que ocorrem no processamento da escrita, sendo basicamente três: planejamento (organização das informações, estabelecimento de objetivos e geração de ideias relevantes), elaboração (observações, anotações e pesquisas a partir das discussões de planejamento) e revisão (avaliação e correção do texto elaborado). Ressalte-se que, embora, em princípio, se possa pensar numa ordenação das mesmas, o processamento de escrita, como os próprios pesquisadores reconhecem - em consonância ao já postulado pela clássica abordagem cognitiva de Flower e Hayes (1981) - não se dá necessariamente de forma sequencial e estanque. As ações relativas a cada fase podem acontecer simultânea e/ ou recursivamente, já que envolvem diferentes processos cognitivos em suas várias subetapas, assim denominadas:

- brainstorming (ou tempestade de ideias: momento inicial, em que os membros do grupo discutem como vão construir o texto) e esboço (fase em que se decide pela direção a ser seguida no texto a ser escrito, bem como suas partes) - na fase de planejamento;

- rascunho (em que se procede propriamente à textualização das ideias, embora ainda em versão inacabada) - na fase de elaboração;

- revisão inicial (revewing, ou primeira revisão, em que se lê o documento e se fazem observações e correções); revisão (revising, ou revisão propriamente dita, em que se revê novamente o texto com alterações que atendem a comentários e observações da revisão inicial) e edição (em que se realizam as últimas alterações e as formatações para o seu acabamento) - na fase de revisão.

Apresentados brevemente os principais conceitos teóricos que nos fundamentam, retratamos, a seguir, os caminhos metodológicos da investigação, para, então, passarmos à leitura analítica dos dados. 


\section{Metodologia da investigação}

Os trabalhos que analisam a produção escrita de natureza colaborativa, conforme pontuam Gaulmyn, Bouchard e Rabatel (2001), costumam, em geral, recair sobre produtos acabados, não sobre o processo de produção; ou são filiados à Genética Textual, "que considera o manuscrito moderno seu objeto de trabalho e local de memória das obras in statu nascendi" (FELIPETO, 2019, p. 134). De modo alternativo, como dispositivo analítico para a compreensão do processo interativo de escrita colaborativa via recursos tecnológicos, adotamos os pressupostos da Análise de Conteúdo (BARDIN, 1979), nosso referencial de natureza metodológica.

De maneira geral, o método - de caráter essencialmente qualitativo, embora permita a utilização de parâmetros estatísticos para embasar as interpretações dos fenômenos, com quadros e tabelas - comporta várias etapas, entre as quais se destacam: a organização da análise, a codificação, a categorização e o tratamento dos resultados, via inferência e interpretação. Assim o explica Bardin (1979, p. 103-104 e 105): "Tratar o material é codificá-lo. [...] Fazer uma análise temática, consiste em descobrir os 'núcleos de sentido' que compõem a comunicação e cuja presença, ou frequência de aparição podem significar alguma coisa para o objectivo analítico escolhido". Na fase final do processo analítico, o pesquisador pode realizar operações estatísticas que lhe possibilitem condensar e pôr em destaque as informações fornecidas pela análise.

Desta forma, sem perder de vista que, na concepção bakhtiniana, o enunciado é a unidade real da comunicação verbal, e não a frase - que é entendida como componente formal da língua(gem), nossa análise de conteúdo considerou a interdependência entre esses dois conceitos nas conversas de WhatsApp dos estudantes. Isso porque, conforme explicitam Sobral e Giacomelli (2016), é possível dizer que a frase tem significação, que é o significado dicionarizado das palavras e expressões, enquanto o discurso, ao materializar-se no enunciado, cria sentido, fazendo com que essas palavras e expressões digam coisas que somente o contexto mostra. E se "a produção do enunciado cria uma união entre a significação das palavras e frases e o seu uso no discurso, e essa união, nos contextos, cria os sentidos do que é dito" (SOBRAL; GIACOMELLI, 2016, p. 1078), foinos possível operar uma análise de conteúdo sob um viés bakhtiniano relativamente aos dados, conforme apresentaremos na sequência.

Os dados do presente estudo foram coletados em 2018, no contexto de duas disciplinas presenciais dos cursos de Letras-Francês e Letras-Espanhol, de uma universidade pública do Paraná, onde atuamos como docente de leitura e produção de textos, junto a 24 alunos de primeira série do período noturno, divididos em pequenos grupos de trabalho formados por três ou quatro integrantes. 
Na ocasião, a ferramenta fórum de discussão da plataforma Moodle era amplamente utilizada por nós como apoio em disciplinas presenciais da graduação; seja por curiosidade tecnológica, seja pelo desejo de conferir as potencialidades interativas da ferramenta defendidas em trabalhos como o de Pereira (2015), por exemplo.

Assim, visando a produção colaborativa de textos acadêmicos dos gêneros discursivos resumo e resenha, solicitamos aos alunos das duas turmas que discutissem por escrito, em grupo, as tarefas de escrita extraclasse, através de um fórum da sala Moodle da disciplina. Seu uso como suporte para a prática da escrita colaborativa parecia-nos viabilizar o desenvolvimento de uma leitura e uma escritura funcionais, dada a possibilidade de enriquecimento das discussões fora do espaço e do tempo da aula, por gerar motivação e engajamento nos estudantes, bem como viabilizar nosso gerenciamento da sua capacidade de interação individual nos grupos de trabalho.

Entretanto, devido a fatores apontados pelos próprios alunos como problemáticos para a adoção da ferramenta como estratégia de interação a distância - necessidade burocrática de senha para acesso à sala Moodle, manutenção do sistema logo após a meia-noite (momento que muitos alunos trabalhadores reservavam para produzir suas tarefas escolares) e dificuldade de acesso via telefone celular -, alguns grupos acabaram optando, espontaneamente, pelo uso alternativo da rede social WhatsApp para suas interações.

As conversas digitalizadas, via fórum ou aplicativo, se referem à discussão, em grupo, acerca de duas tarefas consecutivas de produção textual colaborativa, subdivididas em escrita e reescrita, que visavam, respectivamente, a produção de um resumo de uma reportagem sobre alimentação (NOGUEIRA, 2018) e de uma resenha sobre o filme Com Amor, Van Gogh: o sonho impossível (WELCHMAN; KOBIELA, 2017). A proposta do fórum para discussão do texto a ser resumido foi assim enunciada:

1. PRODUÇÃO COLABORATIVA RESUMO (fórum =2,0 + trabalho escrito $=2,0$ )

PROPOSTA: 1. Leia com atenção o texto Por que o nome "hambúrguer vegano" deve ser proibido por lei, abaixo. [....] 2. Participe do fórum de discussão do seu grupo (valor individual: 2,0 ) conversando POR ESCRITO sobre como vão elaborar um resumo para o texto e formatar o trabalho final [...]. 3. Colabore efetivamente para a produção do texto do resumo, supondo que ele será divulgado em uma página do Facebook para pessoas que não tiveram acesso ao texto e que, portanto, só o conhecerão através do seu resumo. 4. 0 texto do resumo, afora o título, deverá ter entre 15 e 20 linhas (entrelinhamento 1,5). 5. Escreva o texto na modalidade padrão da Língua Portuguesa. 6. Os critérios abaixo serão usados para o julgamento da qualidade de seu resumo [...]. 
De posse dos registros das interações realizadas via Moodle ou WhatsApp, passamos à leitura interpretativa das postagens dos estudantes, a partir dos pressupostos da Análise de Conteúdo de Bardin (1979) e procedemos a uma investigação qualiquantitativa.

Abaixo, seguem algumas análises quanto aos modos è̀s atividades de escrita colaborativa, segundo as categorias de Lowry, Curtis e Lowry (2004), visando responder às nossas questões de pesquisa.

\section{A conversa no Moodle e no WhatsApp sobre a produção colaborativa de resumos e resenhas}

O primeiro aspecto a ser pontuado, com respeito à ferramenta fórum de discussão da plataforma Moodle, foi a resistência dos estudantes, como indicam as postagens abaixo:4

2. [12/7 09:24] Gus: Gente nao consigo mandar nada no moodlw [...]

[12/7 14:19] La: Gente não tô conseguindo entrar no Moodle

[12/7 19:18] Gi: Alguêm conseguiu mandar esse treco?

3. Re: até 02/mai_FÓRUM_RESUMO_De.Ge.Be. (valor individual: 2,0)

por De- quinta, 3 maio 2018, 16:07

Boa Tarde professora, envio aqui o trabalho realizado pela minha equipe ontem. Não utilizamos a plataforma moddlle pois eu estava tendo que usar o celular e o whatsapp era mais prático, posso transcrever a conversa aqui para a avaliação?

Sem contar a influência do fator obrigatoriedade de interagir num ambiente virtual desconhecido, que, pela artificialidade própria da situação de didatização, pode ter contribuído para essa resistência, ambos os grupos mostram dificuldade de acesso à plataforma Moodle, tanto na conversa de WhatsApp (nao consigo mandar nada no moodlw I não tô conseguindo entrar no Moodle / Alguêm conseguiu mandar esse treco), como no depoimento acerca do trabalho (Não utilizamos a plataforma moddlle pois eu estava tendo que usar o celular e o whatsapp era mais prático).

Isso nos leva à percepção clara de que o nível de letramento digital dos estudantes é heterogêneo. Embora os calouros sejam jovens em sua maioria e possam, em tese, ser considerados nativos digitais, segundo a ótica de Prensky (2001), sua prática de uso da tecnologia parece estar circunscrita às redes sociais. De modo que não pode

4 Os nomes dos estudantes foram trocados por apelidos fictícios. Os grifos nas conversas são nossos. 
ser pressuposta como conhecimento partilhado, pelo professor que quer introduzir tecnologia digital como apoio às aulas presenciais, já que o nível de letramento pode interferir não apenas na dinâmica do trabalho docente como nos resultados pedagógicos. Convém, pois, que se faça uma sondagem acerca da experiência de letramento digital dos alunos e se tenha flexibilidade para eventuais ajustes de planejamento, no que se refere a atividades eventualmente previstas envolvendo o uso de plataformas de ensino a distância como apoio ao presencial.

Por outro lado, quando se pretende usar as TDIC como suporte à prática pedagógica, parece ser de bom senso valer-se da prática de letramento digital dos alunos no manejo das redes sociais, como é o caso do WhatsApp, já que, conforme pesquisas recentes, seu uso tem se mostrado produtivo em sala de aula (SENEFONTE; TALAVERA, 2018; BARROS; MELO, 2018). Apostando, pois, na potencialidade das interações também via aplicativo, para o trabalho colaborativo de escrita almejado, solicitamos, aos alunos que o utilizaram, um "copia e cola" da conversa de WhatsApp no espaço do fórum criado especificamente para seu grupo ${ }^{5}$.

Com relação ao que Lowry, Curtis e Lowry (2004) chamam de modos de escrita colaborativa, é forçoso reconhecer que, uma vez que os alunos estavam atendendo a uma tarefa escolar - que, em função da ferramenta indicada (o fórum de discussão Moodle da disciplina ou o grupo de WhatsApp), previamente determinava a modalidade de língua a ser usada na interação extraclasse (escrita) - , a maioria atuou em locais diferentes e em tempos diferentes (via plataforma ou aplicativo). Isso é evidenciado pela própria consigna da atividade e pode ser inferido pela diferença nos dias das postagens, como indica a conversa abaixo, entre Ta (sexta, 4 maio 2018, 17:36) e Le (sábado, 5 maio 2018, 09:52):

4. Re: até 2a.f. 07/mai_FÓRUM_RESUMO_Le.Ta.Man.Isa. (individual: 2,0)

\section{por Ta - sexta, 4 maio 2018, 11:36}

[...] Temos de nos organizar pra ver como podemos desenvolver o resumo em grupo - se trabalharemos por parágrafo, ou se seria melhor sintetizarmos as ideias de mais trechos em conjunto - O que vocês acham?

5. Re: até 2a.f. 07/mai_FÓRUM_RESUMO_Le.Ta.Man.Isa. (individual: 2,0)

por Le - sábado, 5 maio 2018, 09:52

Oi Ta, eu tô com um pouco de dificuldade pra mexer nesse site, assim que eu conseguir achar o texto base eu dou minha opinião hahaha

5 Enquanto no fórum eu participava das interações, no aplicativo elas ficavam restritas ao grupo de alunos. 
Mas houve uma minoria de casos em que a atuação se deu em locais diferentes e ao mesmo tempo, por terem sido feitos com hora marcada, conforme explicita a aluna De, nesta postagem que atende a um pedido nosso de feedback da tarefa:

6. Re: até 02/mai_FÓRUM_RESUMO_De.Ge.Be. (valor individual: 2,0)por De - segunda, 21 maio 2018, 14:48

[...] Sobre o não uso do moodle, principalmente na segunda etapa: como apontado pela Ge, a plataforma não é adapatada para o uso no celular e isso foi um impeditivo bem gande para nós. Além disso, para melhor comunicação, preferimos estar todas online ao mesmo tempo e conversando sobre as pequenas mudanças que precisariam ser feitas [...] Apesar de saber que a questão do uso da plataforma não está em discussão, gostaria de dizer que eu não senti que a plataforma ajudou no processo de fazer o trabalho.

O fato de os alunos terem tido a iniciativa de marcar hora para interagirem a distância, como confessa De (preferimos estar todas on-line ao mesmo tempo) é compreensível, dado que, por serem trabalhadores e estudantes de turno noturno, a realização das tarefas escolares ficava restrita ao espaço de tempo entre o trabalho e a escola, ou entre as aulas da noite, aos finais de semana, ou a outros momentos, como a madrugada, por exemplo, segundo revelam algumas postagens. Sem garantia de estarem on-line todo o tempo, o agendamento da discussão foi a saída encontrada.

Conforme prevíamos, houve, evidentemente, casos esparsos de atuação no mesmo local e ao mesmo tempo, segundo o que alude o estudante Mar, nesta postagem:

7. Re: até 02/mai_FÓRUM_RESUMO_Mar.Gi.Na.Gu. (individual: 2,0)

por Mar - quarta, 9 maio 2018, 14:02

Como alguns estão tendo problemas de acesso ao portal Moodle e algumas das

discussões estão mediadas pessoalmente vou postar uma parte da folha de rosto com orientação obtidas a partir do manual [...]

Provavelmente, em virtude da falta de motivação para a interação escrita via ferramenta fórum, pelas razões já apontadas, e da praticidade da conversação oral, habitual e corriqueira, a demandar muito menos tempo que a escrita - além do que, convenhamos, o contexto era o de um curso presencial - os estudantes se reuniam para discutir presencialmente a tarefa extraclasse em outro horário que não o da disciplina, na própria sala de aula, ou em espaço disponível nas dependências da universidade (como a biblioteca ou a cantina, por exemplo). É o que denuncia a postagem de Mar: algumas das discussões estão mediadas pessoalmente. $\mathrm{E}$ isso, certamente, impactou o registro escrito 
das conversas que, embora valesse parte da nota, muitas vezes demorava a acontecer, dando-se apenas em resposta a alguma cobrança nossa (como se vê abaixo) ou, na maior parte dos casos, dava-se de forma parcial para nós, com quem não era compartilhado o objeto de discurso sobre o qual se conversava - o texto em produção, como se percebe por estas postagens:

8. Re: até 02/mai_FÓRUM_RESUMO_Mar.Gi.Na.Gu. (individual: 2,0) por Li - quarta, 2 maio 2018, 18:07

Alguma dificuldade, gente?

9. Re: até 2a.f. 07/mai_FÓRUM_RESUMO_Ru.Viv.Vit.Vi. (individual: 2,0) por Li - quarta, 16 maio 2018, 11:16

Meninos, a postagem dos trechos do texto que estão sendo discutidos precisa ser aqui, senão não consigo acompanhar. No corpo da mensagem, mesmo.

Essa resistência dos estudantes em fazer por escrito a discussão do texto a ser resumido (contornada pela minha pergunta: Alguma dificuldade, gente?) e de compartilhar conosco as versões intermediárias do texto que estavam produzindo (cobradas por mim: a postagem dos trechos do texto que estão sendo discutidos precisa ser aqui [...]) revela que, para eles, tratava-se de algo absolutamente novo e para o qual não davam a mínima importância; seja porque lhes parecia natural fazer uso de outras formas de interação que não a prevista pela tarefa - como e-mails ou mensagens de WhatsApp para troca de versões textuais parciais ou não definitivas (como alguns me revelaram em aula) - seja porque entendiam se tratar de uma demanda da professora, não deles. Não acostumados nem com a concepção de escrita como processo, nem com a de professor como mediador, pareciam não compreender os motivos de uma atividade que lhes pedia registros de versões intermediárias de um texto a ser produzido. Isso só acabou ocorrendo, mais tarde, e ainda não com todos os grupos, nas discussões acerca do gênero resenha, pois já se tratava da terceira experiência colaborativa no contexto da disciplina, momento em que estavam mais familiarizados com a nossa metodologia de trabalho e passaram a nos encarar mais efetivamente como leitora de suas conversas. O que, de fato, parecia importar aos alunos era o resultado da discussão, ou seja, o texto a ser apresentado como trabalho final para avaliação, como explicita Mar, nesta postagem sobre a resenha:

10. Re: FÓRUM_grupo An.Mar.Tha.Vi.

por Mar - quarta, 4 julho 2018, 14:39

[...] Hoje expira o prazo para entrega do conceito inicial da resenha. Já temos alguma coisa para apresentar? 
É evidente a postura teleológica expressa por Mar em Já temos alguma coisa para apresentar?

Embora o nível de letramento digital deva, também, ser considerado, os dados revelam que os alunos resistem a tudo o que foge de suas práticas tradicionais de letramento e os desafia, conforme justifica Vi neste desabafo:

11. Re: FÓRUM_grupo An.Mar.Tha.Vi.

por Vi - terça, 3 julho 2018, 19:32

Já assisti o filme! Acho que uma resenha tem um caráter muito pessoal da pessoa que a escreve. Uma resenha em grupo será realmente um desafio, pois nem todos tem o mesmo compreendimento e opiniões a respeito de qualquer que seja o tema. Bem, enfim, o jeito é escrever e selecionar as partes com a melhor redação, independentemente de análises positivas ou negativas eu penso.

Tendendo a repetir o modus operandi de produção escrita com o qual estão acostumados, ou seja, individual, Vi qualifica de desafio a tarefa colaborativa de escrita e o enfrenta, propondo uma solução: o jeito é escrever e selecionar as partes com a melhor redação.

Tais dados são sintomáticos de que não é apenas a seleção da plataforma digital que influencia a empatia dos estudantes com a disciplina, o professor e atividade colaborativa de escrita em si mesma, mas igualmente sua própria concepção de escrita, como produto e atividade individual, com a qual nos defrontamos no ensino superior. Afinal, durante toda sua escolaridade básica, os estudantes foram moldados produtores de texto por abordagens de escrita com foco na língua e no escritor, não na interação ou na ação de linguagem em curso.

Na abordagem com foco na língua está subjacente "a concepção de linguagem como um sistema pronto, acabado, devendo o escritor se apropriar desse sistema e de suas regras" (KOCH; ELIAS, 2015, p. 33); o sujeito é concebido como "pré-determinado pelo sistema, o texto é visto com um simples produto de uma codificação realizada pelo escritor a ser decodificado pelo leitor" (KOCH; ELIAS, 2015, p. 33, grifo nosso). Na abordagem com foco no escritor está subjacente a concepção de linguagem como representação do pensamento, de "sujeito psicológico, individual, dono e controlador de sua vontade e de suas ações" (KOCH; ELIAS, 2015, p. 33, grifo nosso) e de texto como "um produto - lógico - do pensamento (representação mental) do escritor" (KOCH; ELIAS, 2015, p. 33, grifo nosso). De modo diverso, na abordagem com foco na interação - a que tem orientado nossa prática docente na universidade - está subjacente a concepção de escrita "como produção textual, cuja realização exige do produtor a ativação de conhecimentos e a mobilização de várias estratégias" de linguagem interacional (dialógica) visando a uma ação de linguagem determinada; de sujeito ativo, como ator/construtor social 
que dialogicamente se constrói e é construído pelo texto, que é considerado "um evento comunicativo para o qual concorrem aspectos linguísticos, cognitivos, sociais e interacionais" (KOCH; ELIAS, 2015, p. 34).

Por isso, o uso das ferramentas tecnológicas em questão, mais do que impactar a escrita colaborativa acadêmica dos estudantes, deu-nos visibilidade às concepções de texto e de escrita que os movia como sujeitos; concepções essas que o escasso tempo de duração da disciplina não conseguiria, por si só, abalar.

No que diz respeito, pois, ao que Lowry, Curtis e Lowry (2004) chamam de atividades de escrita colaborativa, ainda que os registros das conversas pelos estudantes não tenham sido completamente fidedignos à interação que realizaram, há registros de terem vivenciado todas as etapas processuais (recursivas ou não) de produção, tanto no caso do resumo como no da resenha, embora com diferentes índices de ocorrência. Abaixo seguem alguns:

- tempestade de ideias (brainstorming) - Em geral, a discussão do texto-fonte se dava em torno da temática - conforme postagem de Ge, abaixo - e/ou das ideias básicas a serem recuperadas no texto em elaboração - como exemplifica a postagem de Ta:

12. Re: até 02/mai_FÓRUM_RESUMO_De.Ge.Be. (valor individual: 2,0)

por Ge - quarta, 2 maio 2018, 14:44

Eu acredito que a temática do texto gire em torno da rotulagem dos alimentos e da ilusão que isso causa no consumidor, não necessariamente do "vegano" ou "vegetariano", apesar do que sugere o título

13; Re: até 2a.f. 07/mai_FÓRUM_RESUMO_Le.Ta.Man.Isa. (individual: 2,0) por Ta - sexta, 4 maio 2018, 11:36

Oi meninas! Eu li o texto e depreendi que o autor ilustra o marketing falacioso da indústria alimentícia. A rotulagem de produtos vegetais foi utilizada como premissa para o desenvolvimento deste tema, mas o jornalista amplia a discussão ao exemplicar como o consumidor, assim concebido de modo genérico, é enganado pelo modo de apresentação dos alimentos processados.

- esboço - No caso do projeto de texto, como vulgarmente se diz, os comentários incidiram mais sobre a dinâmica da interação colaborativa do grupo (exemplo 14: Podemos escrever o q cada um entendeu... ai separamos por paragrafos) do que especificamente sobre a macroestrutura do texto a ser produzido (exemplo 15: pensei em dividir a Resenha em Sinopse e Crítica): 
14. Re: Tha.Eve.Gu.La.

por Tha - quarta, 2 maio 2018, 18:26

Podemos escrever o q cada um entendeu... ai separamos por paragrafos.

15. Re: FÓRUM_grupo An.Mar.Tha.Vi.

por Vi - quarta, 4 julho 2018, 19:18

Boa Mar, concordo, pensei em dividir a Resenha em Sinopse e Crítica. Como sinopse colocariamos todos os dados técnicos que dispomos sobre o filme e na crítica fariamos todo o restante

- rascunho - Esta foi uma das atividades mais visadas no conjunto de postagens, atestando que a textualização é uma grande preocupação dos estudantes em sua escrita colaborativa:

16. Re: FÓRUM_grupo Vit.Ru.Viv.Isa.

por Viv - sábado, 14 julho 2018, 16:34

Eu gostei bastante da sua resenha, vê oq vc acha da minha

De imenso impacto visual, Com Amor, Van Gogh (Loving Vincent) é um filme que brilha pela proposta estética implementada, seja pela beleza das imagens ou pelo capricho na técnica de animação empregada. [...]

A pergunta de Viv, testando validação dos colegas, precede a apresentação da sua versão do texto da resenha.

- revisão inicial (revewing), revisão (revising), edição (copyediting) - Dada a dificuldade de categorizarmos com precisão os comentários relativamente a essas subetapas, ou atividades específicas, apresentamos abaixo os que parecem se encaixar na categoria maior: a de revisão. Quando o objeto de discussão era a reescrita, notamos que, como reflexo das aulas de análise linguística coletiva que realizamos com os alunos entre as versões iniciais e finais dos textos, os comentários dos grupos acabaram indo além da correção de aspectos formais localizados (como erros de ortografia, ou desvios de concordância e sintaxe), o que evidencia que sua preocupação passou a se centrar em questões de natureza mais global, voltada ao texto como unidade de sentido:

\section{7. [...] [12/7 09:00] Gu: Juntei algumas coisas q eu havia dito}

[12/7 09:01] Gu: Mas ainda sim sintp que falta

[12/7 09:01] Gu: No final, pra dar uma conclusão e falar de alguns pontos q ainda estão perdidos 
[12/7 09:02] Gu: Quero tentar encaixar a parte que a Eve disse que antes era a ideia de um curta

[12/7 09:04] Gu: Indicado, merecidamente, ao Oscar 2018 como Melhor Filme de Animação, "Com Amor, Van Gogh" é, na verdade, o segundo trabalho de Hugh Welchman indicado ao Oscar na categoria. O diretor venceu em 2008, com o curta "Pedro e o Lobo".

18. Re: FÓRUM_grupo Ge.Be.De.Ta.

por Ge - quarta, 4 julho 2018, 13:38

\section{Voces acham que essas mudanças causam um impacto maior?}

"Grandes coisas não se fazem por impulso, mas pela junção de uma série de pequenas coisas". -Van Gogh Esse parece ser o espírito que guiou Dorota Kobiela e Hugh Welchman na produção do longa "Com Amor, Van Gogh", concebido com mais de 65.000 frames pictóricos que [...]

19. [13/7 00:12] Gi: Eu gostei

[13/7 00:12] Gi: Mas tentarei ajeitar algumas coisinhas

[13/7 00:12] Gi: Mas está bom

[13/7 00:17] Gu: beleza

[13/7 02:35] Gi: eu acho que essa parte dos lugares independentes está um pouco estranha

[13/7 02:35] Gi: podemos melhorar essa parte

Tanto os comentários de Gu (Juntei algumas coisas q eu havia dito; Quero tentar encaixar a parte que a Eve disse que antes era a ideia de um curta), quanto os de Ge (Voces acham que essas mudanças causam um impacto maior?) e de Gi (tentarei ajeitar algumas coisinhas; essa parte dos lugares independentes está um pouco estranha; podemos melhorar essa parte) expressam claramente uma preocupação para além da gramática.

Mesmo havendo evidências qualitativas de que a discussão dos alunos versou sobre todo esse conjunto de atividades de escrita colaborativa, previstas por Lawry, Curtis e Lawry (2004), vale notar que, em termos quantitativos, houve diferença de focalização nas conversas dos grupos, como apresentamos na Tabela 1 abaixo: 
Tabela 1. Atividades de escrita colaborativa em fóruns de discussão e WhatsApp

\begin{tabular}{c|c|c|c}
\hline \multirow{2}{*}{ Planejamento } & Atividade & Porcentagem & Total \\
\cline { 2 - 3 } & esboço & $28 \%$ & $31 \%$ \\
\hline Elaboração & rascunho & $33 \%$ & \multirow{2}{*}{$69 \%$} \\
\hline Revisão & $\begin{array}{c}\text { revisão inicial (revewing) } \\
\text { revisão (revising) } \\
\text { edição }\end{array}$ & $36 \%$ & \\
\hline
\end{tabular}

Fonte: Elaboração própria

A atividade de revisão foi a que congregou mais atenção por parte dos mesmos, com $36 \%$ das postagens, o que certamente se explica pelo fato de termos investido bastante na ideia da reescrita como parte do processo produtivo, inclusive em nossas intervenções de correção entre as versões.

A despeito desse resultado, contudo, independentemente do fato de se tratar de primeira ou segunda versão, a fase que também teve significativa atenção dos estudantes foi, como já imaginávamos, a de elaboração, com 33\% das postagens fazendo referência ao rascunho do produto final a ser apresentado, seja relativamente ao resumo ou à resenha.

Já quando se trata de planejamento, chama a atenção o forte contraste entre o alto número de postagens relativas à tempestade de ideias (28\% das ocorrências) e a quase inexistência de postagens relativas ao esboço (3\%).

No primeiro caso (brainstorming), houve quase o dobro de discussões temáticas voltadas à resenha (35\%) em comparação com as referentes ao resumo (20\%); resultado compreensível, já que o julgamento do texto a ser resenhado demanda um esforço de consenso muito maior, por parte dos escreventes, quanto à opinião a ser veiculada no texto em construção. Mas raramente se observam discussões em torno de como proceder à textualização dessa mesma opinião.

Quanto ao segundo caso (esboço), o projeto de texto parece não ser uma atividade de produção para o qual deem atenção e/ou atribuam valor, seja para que gênero for. Tudo se passa como se fosse automática a passagem da ideia projetada metadiscursivamente à efetiva textualização. Isso pode indiciar que a atividade de arquitetagem, mapeamento ou projeção da macroestrutura textual pode não ter sido objeto de ensino-aprendizagem na educação básica; os estudantes se mostram muito mais familiarizados com a discussão temática no nível da compreensão do que no da produção. 
É forçoso, entretanto, reconhecer que alguns alunos parecem ter uma noção, ainda que pálida, da importância do planejamento no estabelecimento de uma razoável arquitetura do dizer. Isso ficou evidente em algumas postagens metadiscursivas, mas elas não configuram, propriamente, um projeto claro de textualização, seja do resumo ou da resenha a ser produzida.

Assim, a menor incidência de registros de discussão de leitura (28\%), seja do texto a ser resumido ou do filme a ser resenhado, aliada à quase inexistente ocorrência de conversas acerca de projetos de texto (3\%), contrasta com a forte presença de postagens sobre rascunhos (33\%) - inclusive tomados, às vezes, como textos praticamente acabados - e revisões (36\%). Percebe-se, portanto, que, quando os estudantes discutem a escrita colaborativa de resumos e resenhas, a preocupação com o que dizer (típica da etapa de planejamento: brainstorming e esboço) é muito menor (com 31\% das ocorrências) relativamente à circunscrita ao como dizer (típica das etapas de elaboração e revisão, com $69 \%$ dos casos).

O que poderia, então, explicar esses resultados?

\section{Considerações (não tão) finais}

A análise da construção do texto colaborativo por aprendizes de escrita acadêmica em interações via ferramenta fórum da plataforma Moodle e do aplicativo WhatsApp nos permitiu achados interessantes.

Os modos e as atividades de escrita colaborativa desenvolvidos por estudantes de Letras na modalidade presencial em interação assíncrona (pré-pandêmica) podem ser entendidos como estratégias corriqueiras de produção textual conjunta na graduação. E evidenciam, segundo demonstramos, a herança de uma orientação pedagógica anterior à universidade, centrada numa abordagem de ensino e aprendizagem da escrita entendida como produto (KOCH; ELIAS, 2015). Isso nos leva a inferir que a vivência dos sujeitos aprendizes, durante sua escolarização, esteve pautada teleologicamente e formatada pelo modelo de habilidades proposto por Lea e Street (1998), pois, embora a expressão letramentos acadêmicos tenha sido originalmente desenvolvida visando ao estudo em nível superior, o conceito também se aplica ao período que vai da educação infantil ao Ensino Médio.

O fato de os estudantes serem levados a interagir via ferramentas tecnológicas digitais de conversação, para produzir colaborativamente seus primeiros textos acadêmicos na universidade, parece, pois, insuficiente para alterar significativamente, de per si, suas concepções anteriores de escrita como produto, resultado do esforço individual, trazidas da educação básica. Ao contrário, só dão mais visibilidade às mesmas. E o fato de serem levados a interagir pela escrita para falar acerca da escrita, via recursos tecnológicos, 
parece igualmente uma experiência insuficiente para demovê-los de uma concepção autônoma de letramento (STREET, 1995), vivenciada, igualmente, durante toda sua escolaridade pré-universitária. Tal concepção é revelada nas conversas digitalizadas, tanto na plataforma Moodle quanto no aplicativo WhatsApp, quando reforçada pelos pares em seus turnos conversacionais: a preocupação centrada mais em aspectos linguísticos que discursivos da textualização, a desconsideração da natureza processual da escrit(ur)a e o desconhecimento da concepção de escrita como trabalho - processo contínuo e complexo que abarca um esforço individual: "um trabalho consciente, deliberado, planejado, repensado" (FIAD; MAYRINK-SABINSON, 2001, p. 63).

Embora tivéssemos por hipótese que - dada a própria natureza dialógica da escrita digitalizada em contexto de aprendizagem, a requerer do aluno produtor maiores explicitações para seus colegas de grupo -, a conversa assíncrona pudesse potencializar a atenção dos estudantes para com o aspecto processual da escrita, favorecendo o desenvolvimento de seu letramento acadêmico, o que os dados nos mostram vai numa direção diversa. Eles não apenas indicam que os alunos tendem a repetir posturas previamente adquiridas, como igualmente mostram que eles dependem de uma atenta mediação do professor para delas se demoverem. Como as produções de resumo antecederam as de resenha, na disciplina, ficou bastante clara a diferença na tematização das postagens relativas a um e a outro gênero que atestam mudanças significativas nesse sentido, provavelmente promovidas em função da nossa intervenção docente no processo - seja em função das aulas de análise linguística coletiva em sala, seja das devolutivas que fizemos com correções dos textos - o que indica a pertinência de investigarmos esse aspecto da mediação docente, em específico, em novas oportunidades.

Até que isso ocorra, vale frisar que é grande o número de variáveis interferentes no processo de produção colaborativa do texto acadêmico escrito a demandar atenção por parte do professor universitário pesquisador interessado em alterar minimamente esse estado de coisas, incluindo as atinentes à incorporação de recursos de tecnologia digital como apoio ao desenvolvimento do letramento acadêmico.

\section{REFERÊNCIAS}

BAKHTIN, M. M. Estética da criação verbal. São Paulo: Martins Fontes, 2003 [1952-1953, 1974].

BARDIN, L. Análise de Conteúdo. Lisboa: Edições 70, 1979.

BARROS, L. S. F.; MELO, M. A. T. de. O WhatsApp como ferramenta motivadora no ensino da produção escrita. In: CONGRESSO INTERNACIONAL DE EDUCAÇÃO E TECNOLOGIA, 4, 2018, [S.I.]. Anais... São Carlos. Disponível em: https://cietenped.ufscar.br/submissao/ index.php/2018/article/view/727/266. Acesso em: 30 set. 2020. 
BARTON, D. Literacy: an introduction to the ecology of written language. Oxford: Blackwell, 1994.

BRASIL. Ministério da Educação. Base Nacional Comum Curricular. Brasília, 2018.

BRASSAC, C. Rédaction coopérative: un phénomène de cognition située et distribuée. In: GAULMYN, M.-M. de.; BOUCHARD, R.; RABATEL, A. (ed.). Le processus rédactionnel: écrire à plusieurs voix. Paris: L'Harmattan, 2001. p. 49-66.

CASTELLS, M.; CARDOSO, G. (org.). A Sociedade em Rede: do conhecimento à ação política; Conferência. Belém (Por): Imprensa Nacional, 2005.

FELIPETO, S. C. S. Escrita colaborativa e individual em sala de aula: uma análise de textos escritos dos alunos do ensino fundamental. Alfa, São Paulo, v. 63, n. 1, p. 133-152. 2019. Disponível em: https://www.scielo.br/scielo.php?script=sci_ arttext\&pid=S1981-57942019000100133. Acesso em: 30 set. 2020.

FIAD, R. S.; MAYRINK-SABINSON, M. L. T. A escrita como trabalho. In: MARTINS, M. H. (ed.). Questões de linguagem. São Paulo: Contexto, 2001. p. 54-63.

FLOWER, L.; HAYES, J. R. A Cognitive Process Theory of Writing. College Composition and Communication English, 41, Illinois, p. 365-387. 1981. Disponível em: https://www. semanticscholar.org/paper/A-Cognitive-Process-Theory-of-Writing.-Flower-Hayes/ c8ff58b5db4cf03fcf2c94b2b825e93ab43bcbcd. Acesso em: 15 jul. 2020.

GAULMYN, M-M.; BOUCHARD, R.; RABATEL, A. Le processus rédactionnel: écrire à plusieurs voix. Paris: L'Harmattan, 2001.

GEE, J. P. Social linguistics and literacies: ideology in discourse. London: The Farmer Press, 1996.

HORTON, M.; ROGERS, P.; AUSTIN, L.; MCCORMICK, M. Exploring the impact of faceto-face collaborative technology on group writing. Journal of Management Information Systems, v. 8, n. 3, p. 27-48, 2004 [1991]. Disponível em: https://www.jstor.org/ stable/40398006?seq $=$. Acesso em: 21 maio 2020.

KOCH, I. G. V.; ELIAS, V. M. Ler e escrever: estratégias de produção textual. 2. ed. São Paulo: Contexto, 2015. 
LEA, M. R.; STREET, B. V. Student writing in higher education: an academic literacies approach. In: LEA, M. R.; STREET, B. V. Studies in Higher Education, Abingdon, Oxon, UK, v. 23, n. 2 , p. 157-172, 1998.

LEA, M.R.; STREET, B. V. Writing as academic literacies: understanding textual practices in higher education. In: CANDLIN, C. N.; HYLAND, K. (ed.). Writing: texts, processes and practices. London: Longman; 1999. p. 62-81.

LEA, M. R.; STREET, B. V. O modelo de "letramentos acadêmicos": teoria e aplicações. Tradução de Fabiana Komesu e Adriana Fischer. Filologia e Linguística Portuguesa, São Paulo, v. 16, n. 2, p. 477-493, 2014. Título original: The "academic literacies": model: theory and applications. Disponível em: http://www.revistas.usp.br/flp/article/view/79407. Acesso em: 13 out. 2020.

LÉVY, P. A nova relação com o saber. In: LÉVY, P. Cibercultura. Tradução Carlos Irineu da Costa. São Paulo: Editora 34, 1999. p. 159-170.

LILLIS, T.; SCOTT, M. Deining academic literacies research: issues of epistemology, ideology and strategy. Journal of Applied Linguistics, v. 4, n. 1, p. 5-32, 2007. Disponível em: http://www.equinoxpub.com/JAL/article/viewArticle/4563. Acesso em: 21 maio 2020.

LOWRY, P.; CURTIS, A.; LOWRY, M. Building a taxonomy and nomenclature of collaborative writing to improve interdisciplinary research and practice. Journal of Business Communication, Blacksburg, n. 41, v. 1, p. 66-99, 2004. Disponível em: https:// pdfs.semanticscholar.org/e11a/466f77c4371d57fa6c8e992c8f5798a95ee1.pdf. Acesso em: 21 maio 2020.

MATEUS FILIPE, A. J.; ORVALHO, J. G. Blended-Learning e Aprendizagem Colaborativa no Ensino Superior. Anais do VII Congresso Iberoamericano de Informática Educativa, 2004. Disponível em: http://www.niee.ufrgs.br/eventos/RIBIE/2004/comunicacao/com216225.pdf. Acesso em: 01 jun. 2020.

NOGUEIRA, VI. Por que o nome "hambúrguer vegano" deve ser proibido por lei. Folha de S. Paulo on-line, de 24/04/18. Disponível em: https://cozinhabruta.blogfolha.uol.com. br/2018/04/24/por-que-o-hamburguer-vegano-deve-ser-proibido-por-lei/?loggedpaywall. Acesso em: 27 set. 2020.

PEREIRA, A. U. O fórum de discussão no ensino da língua portuguesa: explorando a escrita argumentativa em artigo de opinião. 2015. Dissertação (Mestrado em Letras) - Profletras, Pau dos Ferros, Rio Grande do Norte, 2015. Disponível em: http://www.uern.br/controledepaginas/ defesas2015/arquivos/3539aline_uchoa_pereira.pdf. Acesso em: 30 jul. 2016. 
PEREIRA, E. B. Do letramento digital ao acadêmico: dinâmica interacional e práticas de escrita no Facebook. Revista Linha D'Água, São Paulo, v. 28, n. 1, p. 67-86, jun. 2015. Disponível em: http://www.revistas.usp.br/linhadagua/article/view/96988. Acesso em: 30 maio 2010.

PINHEIRO, P. A. A escrita colaborativa por meio do uso de ferramentas digitais: ressignificando a produção textual no contexto escolar. Calidoscópio, Porto Alegre, v. 9, n. 3, p. 226-239, 2011.

PRENSKY, M. Digital Native, digital immigrants. On the Horizon, MCB University Press, v. 9, n. 5, out. 2001.

SENEFONTE, F. H. R.; TALAVERA, M. N. G. O WhatsApp como ferramenta no ensinoaprendizagem de língua inglesa. Entretextos, Londrina, v. 18, n. 1 sup., p. 241-264. Dossiê Temático/2018. Disponível em: http://www.uel.br/revistas/uel/index.php/entretextos/ article/view/33971. Acesso em: 30 set. 2020.

SOBRAL, A.; GIACOMELLI, K. Observações didáticas sobre a análise dialógica do discurso - ADD. Domínios de Lingu@gem, v. 10, n. 3, p. 1076-1094, 2016.

SOUNDERS, W. M. Collaborative writing tasks and peer interaction. International Of Educational Research, [S. I.], p. 101-112, 1989. Disponível em: https://doi. org/10.1016/0883-0355(89)90019-0. Acesso em: 30 set. 2020.

STREET, B. V. Literacy in theory and practice. Cambridge: Cambridge University Press, 1984.

STREET, B. V. Social Literacies: Critical Approaches to Literacy in Development, Ethnography and Education. Harow: Pearson, 1995.

STREET, B. V. What's "New" in New Literacy Studies? Critical approaches to literacy in theory and practice. Current Issues in Comparative Education. Teachers College, Columbia, University, 2003.

TORRES, T. Z.; AMARAL, S. F. do. Aprendizagem Colaborativa e Web 2.0: proposta de modelo de organização de conteúdos interativos. ETD - Educação Temática Digital, Campinas, v. 12, n. esp., p. 49-72, abr. 2011.

WELCHMAN, H.; KOBIELA, D. Com Amor, Van Gogh: o sonho impossível. Reino Unido; Polônia. Animação, cor, 95 min., 2017.

WIGGLESWORTH, G.; STORCH, N. Pair versus individual writing: effects on fluency, complexity and accuracy. Language Testing, [S.I.], v. 26, n. 3, p. 445-466, 2009. 